\title{
RESEARCH OF THE BEHAVIORAL RISK FACTORS WITH ELDERLY PEOPLE IN THE CONTEXT OF THE CONTEMPORARY VISION FOR HEALTH PROMOTION
}

\author{
Tanya Paskaleva ${ }^{1}$, Snezhana Dragusheva ${ }^{2}$ \\ ${ }^{1}$ Trakia University of Stara Zagora, Branch of Haskovo \\ 48, "Saedinenie" blvd., Haskovo, Bulgaria \\ mobile: +359885 333402, e-mail: paskaleva666@abv.bg \\ ${ }^{2}$ Nursing Care Department, Medical University, Plovdiv, Bulgaria \\ mobile: +359 887 204359, e-mail: sdragusheva68@gmail.com
}

\begin{abstract}
One of the key approaches to preserving health and lengthening human life, including these with the elderly people, is to decrease the impact of the risk factors - smoking, excessive use of alcohol, incorrect feeding, lack of physical activity and others. The combination of two and more of the stated risk factors, with a definite longevity, is a prerequisite of an increased health risk, and also give rise and development of pathological changes and premature ageism.

Aim: Research and analysis of the behavioral risk factors with elderly people in the context of the contemporary concept for health promotion.

Materials and methods: There has been conducted anonymous research with elderly people in the region of Haskovo for the period January - April 2016, all of them determined by accidental choice. In the research took part total of 142 people, aged from 65 to 75 and more. The data has been statistically processed with the help of SPSS 12.

Results: The analysis of the health status of the respondents shows multiple pathology - the highest is the rate of the coronary diseases - $60 \%$. Nearly half of the elderly people have two and three diseases and $35 \%$ more than three. There exists a widespread distribution of behavioral risk factors - low physical activity, obesity $57,8 \%$, smoking $31 \%$, alcohol misuse $25 \%$.

Conclusion: The effective control over the individual risk profile and the timely correcting actions in a devitalized way of life guarantee active and sufficient old age.
\end{abstract}

Keywords: elderly people, risk factors, health promotion.

\section{INTRODUCTION}

Humankind is getting older with rapid speeds. The statistics persuasively confirms this world tendency and the segment of the population that is aged 65 and more is more than $600 \mathrm{ml}$ people. In Bulgaria by 2060 the elderly population aged 65 and more as a percentage of the whole population is expected to increase with 12,3 percent and reach $32 \%[3,8]$.

Old age is a clearly identifiable time point, in which together with the problems due to the evolutionary processes, people should not underestimate those, connected to morbidity. The growing polimorbidity increases the frequency of temporary or permanent incapacity for work, and is also connected to significant necessity of special care and risk of complications. The best way to ensure good health to the future cohort of elderly people is through prophylactics of the diseases and health promotion throughout the whole life. Health promotion is a reflection of the idea for widespread social prophylactic, implemented in the efforts of the people themselves. The person changes their position from an object of medical help into a subject of their own health. Health promotion views personality as the main resource of healthcare. From this comes the decisive meaning of the personal health culture and personal health behavior $[1,6]$.

IRTIIE Vol. 5, No. 3, 2017 ISSN 1314-8788 (print), ISSN 1314-8796 (online), doi: 10.15547/artte.2017.03.011 


\section{ARTTIE $Y$}

Ipplied Resseirlores in Technics, Technologies and Educration

Journal of the Faculty of Technics and Technologies, Trakia University https://sites.google.com/a/trakia-uni.bg/artte/

There are observations and scientific analysis that show that the key whether a person would be ill or healthy, would live long or would die prematurely, is hidden in a number of individual behavioral factors like smoking, excessive use of alcohol, incorrect feeding, lack of physical activity and others [3].

The combination of two and more from the risk factors stated above, with a definite longevity, is a prerequisite for an increased health risk, and also give rise and development of pathological changes and premature ageism.

AIM: Research and analysis of the behavioral risk factors with elderly people, in the context of the contemporary concept for health promotion.

\section{METHODS}

There has been conducted an anonymous research with elderly people in the region of Haskovo in the period between January - April 2016, all of them determined by accidental choice. The questionnaire card includes questions connected to the most important behavioral risk factors that influence the development of chronic illnesses in advanced age physical activity, overweight, misuse of alcohol and smoking. The data has been statistically processed with the help of SPSS 12.

\section{RESULTS}

In the research took part total of 142 people, aged from 65 to 75 or more. The biggest is the age group 65-69 - 46\%. The percentage distribution according to gender is as follows: almost two thirds of the questioned $60 \%$ are women and $40 \%$ are men. Compared by family status the biggest group is with the married $53 \%$, followed by $42 \%$ of the lonely people widower/widow. The distribution of the respondents according to education shows that more than half have high school diploma $(34,8 \%)$ and primary school diploma $(34,8 \%)$. Considerably smaller is the number of people with a university $(11,3 \%)$ and college $(12,8 \%)$ education. Without any education are $6,4 \%$. Most of the questioned are pensioners with age $-71,6 \%$, and $14,9 \%$ are pensioners on behalf of an illness. $13,5 \%$ of the people report that they work.

The chronic non-infectious illnesses have been an important socio-medical problem with the elderly people for decades. Our research showed that with $60 \%$ of all respondents there have been registered diseases of the coronary system, followed by those of the endocrine system $(26 \%)$, respiratory system $(18 \%)$, bone-muscle system $(16 \%)$ and others.

A characteristic feature of the pathology of this age diapason is its multitude. Only $16 \%$ of the questioned people have only one disease, $49 \%$ have pointed out two and three diseases and $35 \%$ more than three.

The diseases of the coronary system with the elderly people are a main reason for disability and death, and are also a basic factor for limitation and appearance of psychological problems. The specified groups of diseases are with social importance and could be connected with the negative influence of a number of risk factors emerging from the way of life, environmental pollution, alcohol misuse, smoking, stress and others. We also should not neglect the formalized attitude to the health promotion and prophylactics of the diseases, which in its greater extent are neglected and underestimated.

The research showed that women suffer more than men - they point out more chronic diseases. Considering this matter, our results coincide with other research.

The question with the physical activity has permanently been presented in all cultures since Antiquity. Today in the times of the technical civilization, when conformity and facilitation have overwhelmed all spheres of social life, people talk more and more about hypokinesias as a problem that deteriorates. That's why the active policy to encourage physical activity is a

IRTIIE Vol. 5, No. 3, 2017 ISSN 1314-8788 (print), ISSN 1314-8796 (online), doi: 10.15547/artte.2017.03.011 


\section{ARTTIE $Y$}

Ipplied Resseirlohes in Technics, Technologies and Eductition

Journal of the Faculty of Technics and Technologies, Trakia University https://sites.google.com/a/trakia-uni.bg/artte/

priority not only on European, national, regional, but also on a local level. The global tendencies for promotional-preventive and prophylactic direction of the medicine place the physical activity in the focus of a number of programs and strategies that define the common aims for action, the directions and the parameters of the activity of each age group.

Motive activity is amongst the main factors that influence the quality of life and has considerable contribution to the health and well - being of every human.

Consider the data representing the self-assessment of the physical activity. It makes impression that the moderate activity prevails with the majority of the respondents $-51 \%$, but what is alarming is the result of the $41 \%$ of the respondents who define their activity as low. With the advancing of age the time that the elderly people spend for physical activity is getting smaller and smaller. The results are troublesome with $41 \%$ from the questioned men and $33 \%$ of the women who spend less than 1 hour per week. For the people who live in a village, there is observed higher level of physical activity.

Amongst the most usual motifs for implementing physical activity the respondents point out good health (men $79 \%$ and women $73 \%$ ). The barrier for the biggest part of the respondents for the two genders is pointed out as the presence of an illness (men 53\%, women 49\%), which is a reason for general weakness and reluctance.

Obesity is a complex multi-factual disease and a real health problem, which is positioned as priority not only for the European region, but also for our country. The reasons for this social and medical problem are rooted in the unhealthy model of feeding, motive deficiency and others. The elderly people are with a high degree of vulnerability to being obese, which in respect is an entrance to a number of serious health problems. If obese, the possibility of development of coronary diseases, diabetes, some kinds of cancer, bone-muscle problems and others considerably increases.

In order to assess the distribution of the overweight, obesity and the risk that is connected with it, within the population is used the body mass index (BMI).

The results of our research show that the biggest is the group of the people who are overweight $45,8 \%$ for the two genders. The results are alarming for $14 \%$ of the women and $8,9 \%$ of the men who are obese with 1 and 2 degree, which itself represents a high risk of becoming ill (Table 1).

Table 1. Body mass index according to gender

\begin{tabular}{|c|c|c|c|c|c|c|}
\hline \multirow[t]{2}{*}{ Classification } & \multicolumn{2}{|c|}{$\begin{array}{c}\text { Men } \\
\mathrm{n}=56\end{array}$} & \multicolumn{2}{|c|}{$\begin{array}{c}\text { Women } \\
n=86\end{array}$} & \multicolumn{2}{|c|}{$\begin{array}{c}\text { Total } \\
\mathrm{n}=142\end{array}$} \\
\hline & $\mathrm{n}$ & $\%$ & $\mathrm{n}$ & $\%$ & $\mathrm{n}$ & $\%$ \\
\hline $\begin{array}{l}\text { Undernorm weight } \\
(\mathrm{BMl}<18,5)\end{array}$ & 1 & $1,8 \%$ & 2 & $2,3 \%$ & 3 & $2,1 \%$ \\
\hline $\begin{array}{l}\text { Normal weight limits } \\
\text { (BMl } 18,5-24,9)\end{array}$ & 23 & $41,1 \%$ & 34 & $39,5 \%$ & 57 & $40,1 \%$ \\
\hline $\begin{array}{l}\text { Overweight } \\
\text { (BMI 25,0-29,9) }\end{array}$ & 27 & $48,2 \%$ & 38 & $44,2 \%$ & 65 & $45,8 \%$ \\
\hline $\begin{array}{l}\text { Obesity } 1^{\text {st }} \text { and } 2^{\text {nd }} \text { degree } \\
(\mathrm{BMI}>30,0)\end{array}$ & 5 & $8,9 \%$ & 12 & $14 \%$ & 17 & $12 \%$ \\
\hline
\end{tabular}

Another problem characteristic of our times is the unbalanced feeding, which with the advancing of age is connected to a number of diseases - atherosclerosis, diabetes, obesity, anemia, hypertonic disease and others.

According to Tchebotarev D. F. feeding - practically, is the only means that lengthens life with $25-40 \%$ [7].

An important principle in the gerodiet in the prophylactics of the premature ageing is the balanced feeding in compliance with the energy loss of the organism. As the age advances IRTIIE Vol. 5, No. 3, 2017 ISSN 1314-8788 (print), ISSN 1314-8796 (online), doi: 10.15547/artte.2017.03.011 


\section{AR'IIE \\ ( \\ Ipplied Resseirlores in Technics, Technologies and Educration \\ Journal of the Faculty of Technics and Technologies, Trakia University https://sites.google.com/a/trakia-uni.bg/artte/}

the metabolic processes become slower. The tissue breathing declines, which itself imposes gradual decline of the energy from the eaten food [4].

Conducting active propaganda for a healthy way of life, including the principles for rational feeding during the past 30 years in the USA, has brought to a decline of the death rate from a coronary pathology with $40 \%$ and $2 / 3$ of this effect is due to the changes in the eating habits. It has also been established that rational feeding leads to considerable cureprophylactic effect, which on an organic level emerges after 1-2 years and on the level of population (increasing the average life expectancy, decreasing the death rate) - 10 years after the corrections made [5].

An important role in the prevention plays the change of the lifestyle with an accent over modification of the feeding behavior. Applying effective preventive measures in this respect is possible only when there is conducted a systematic monitoring of the eating habits of every person.

The results from the answered questions connected to the eating habits of the respondents show that there prevails the threefold feeding regime with the two genders $(39 \%$ men and $53 \%$ women).

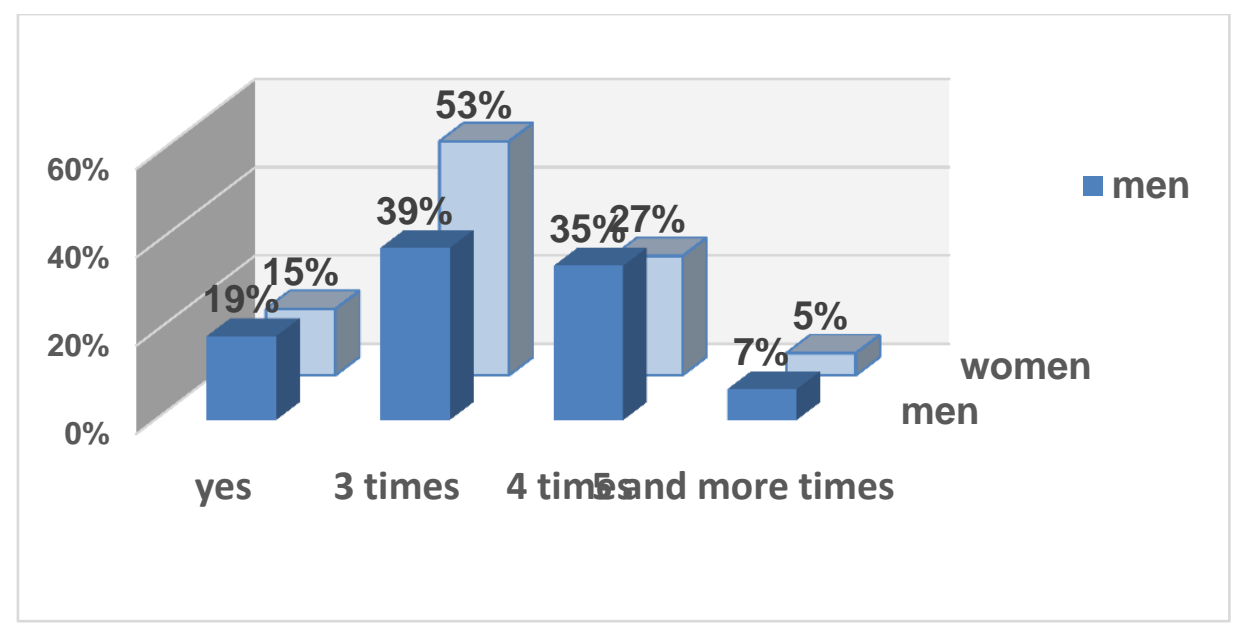

Figure 1. Feeding regime

The most rational is the fourfold feeding - the first breakfast should contain $25 \%$ of the whole day-and-night calorie rate, the second $-15 \%$, lunch $-35 \%$ and dinner $-25 \%$. The last reception should be 2-3 hours before going to bed [5].

Alarming is the data with $19 \%$ of the men and $15 \%$ of the women, who have pointed out lesser than the threefold feeding per day. Positive can be the fact that the majority of the questioned $75 \%$ point out that they eat at one and the same time, which is due to an established eating regime.

In connection to the factors from which the choice of food depends, in the hierarchy for both genders, the preferred taste leads with $65 \%$, which itself is linked to a no good knowledge as far as the principles of gerodiet are concerned. For a second place $28 \%$ state that the food prices are determinative.

Balanced feeding is a mission possible but it is not only will and sensible choice that are sufficient. A real reason for the difficulties the feeding to be of full value and healthy is the low incomes that often put elderly people in the position of complex choices and destitutions. We should also not underestimate a number of factors that influence feeding unfavorably, and namely: chronic illnesses, cognitive disorders, aggravated teeth status with missing or bad 


\section{ARTTIE $Y$}

Ipplied Resseirlores in Technics, Technologies and Educration

Journal of the Faculty of Technics and Technologies, Trakia University https://sites.google.com/a/trakia-uni.bg/artte/

dentures, economic difficulties, reception of a number of medicaments (that deteriorate appetite), change of the taste qualities and others.

The daily consumption of fresh fruit and vegetables is an important characteristic of the healthy eating. According to the recommendations of the WHO there should be consumed at least 400,0 a day vegetables and fruit [9]. Our research established that almost $1 / 2$ of the questioned daily include in their menu fruit and vegetables, and for the other $1 / 2$ of the respondents, the consumption is really insufficient.

To the question: „Do you consume milk and dairy products?“, it turns out clear that $1 / 2$ of the questioned from both genders consume daily these products, which have an important biological role in feeding. Alarming is the fact that $33 \%$ men and $28 \%$ women consume these products once a week, $2 \%$ men and $6 \%$ women once a month and $7 \%$ men and $11 \%$ women rarely than that, which is really insufficient. The low reception of calcium, especially with people over 60 is too risky. The insufficient reception increases the possibility of osteoporosis.

In the biggest part of the cases the bean foods are represented once a week in the menu $47 \%$ men and $33 \%$ women. For a daily reception of meat and meat products report $42 \%$ of men and considerably less $19 \%$ of women. The bigger part of them consumes them once a week $-44 \%$ men and $52 \%$ women.

When assessing the answers about the feeding habits for the two genders it makes impression the high rate of men and women that consume fish rarely - men 35\% and women $60 \%$. Almost $1 / 3$ is the part of those, who consume fish once a month. The recommendations of the WHO, 2003 are for consumption of fish 1-2 times a week, having in mind fish and fish products are rich in PNMC [9].

The reception of sweets and pastry should be mainly limited because of the negative effect over the body mass. That is why the presence of obesity is mostly connected to their increased consumption. The data analysis shows that there prevail the answers for daily consumption, not only for men - 39\%, but also for women - 33\%.

To the question: „Do you put extra salt on your food?" - $40 \%$ of the men and $25 \%$ of the women have the habit to add salt to their meals. With the elderly people decreases the saltgustatory bud sensitivity, which is often a reason for the excessive use of salt. In this connection we should not forget the recommendations of the WHO for a limited reception of salt up to 5-6 gr. daily and the fact that the increased reception is a risk factor for obesity and coronary diseases [10].

Smoking is one of the proved, leading preventable causes for diseases and death. According to data of the WHO every year more than 5,6 million people in the whole world die prematurely of diseases connected to smoking. Up to 2030 the death rate is expected to reach 8 million per year. If such tendencies continue, during the 21st century smoking will be the cause of more than 1 billion people. It is believed that more than $80 \%$ of these death cases will be in countries with low incomes. In Europe smoking forms 12,2\% of the global burden of the diseases and is a reason for $21 \%$ of all lethal cases [3].

In the medical informational space there a sufficient number of research that show the damage from the smoking. It is amongst the behavioral risk factors that are associated with a number of chronic diseases in the group of the elderly people.

To the question - "Do you smoke?" - $42 \%$ of the questioned men are active smokers and from the women $-30 \%$. The results from the self-assessment of the health amongst the smokers point out that the majority of them define their health as satisfactory - $52 \%$, with no substantial gender differences. 


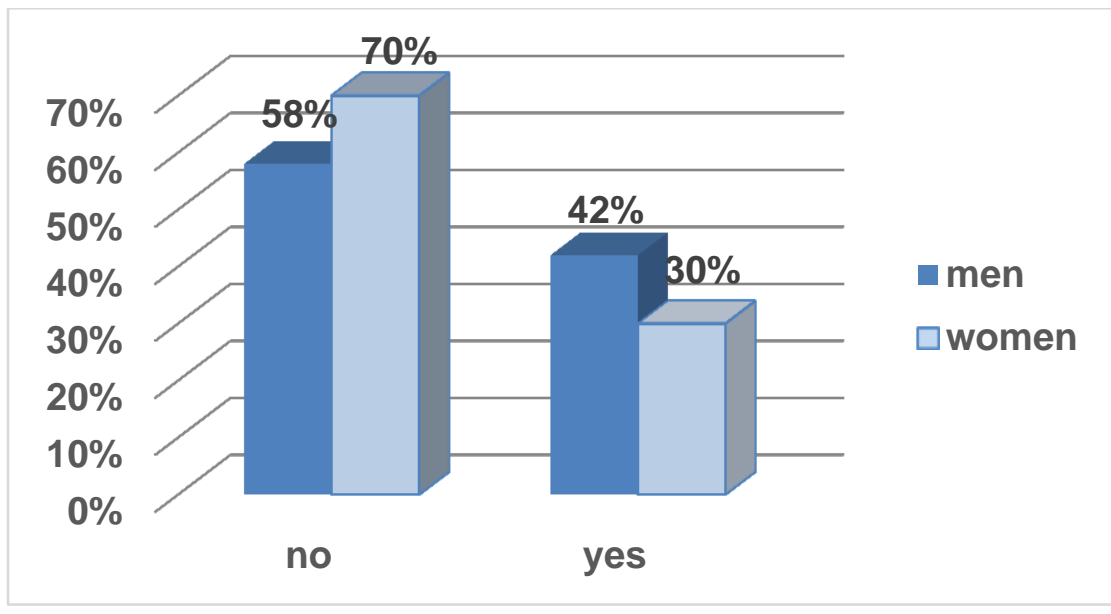

Figure 2. Smokers according to gender

As with smoking, the excessive use of alcohol not only increases the risk coronary pathology, cancer, stomach ulcer and others, but is also one of the factors for death in result of intoxication with alcohol, road accidents, homicides and suicides. Alcohol deteriorates the health status and intensifies chronic diseases, which escalate in the group of the elderly people and is an essential reason for premature death.

In the European Union the damaging and risky consumption of alcohol is the third biggest risk factor for aggravated health, responsible for 195000 lethal cases every year, being 12\% of the premature death with the men and $2 \%$ of the premature death with the women [3].

One of the questions in the questionnaire card, addressed to the way of life is connected to the consumption of alcohol. The results discussing this problem show that $27 \%$ of the questioned women and $23 \%$ of the men consume alcohol/concentrate every day.

\section{DEDUCTION}

- The analysis of the health status of the questioned people shows various pathology - the highest is the rate of the coronary diseases- $60 \%$.

- $49 \%$ of the elderly people have two and three diseases and $35 \%$ more than three.

- There is a widespread distribution of behavioral risk factors - low physical activity, obesity $57,8 \%$, smoking $31 \%$, alcohol misuse $25 \%$.

- With considerable part of the elderly people there is observed unbalanced feeding regime, which is a prerequisite of an increased health risk.

- A large part of the observed risk factors are modifiable and, through timely, effective prophylactic activities, can be prevented.

\section{CONCLUSION}

In the efforts directed at reducing the risk factors there are needed innovative approaches and strategies. It is necessary to have positive attitude to health, through increasing the health culture and taking a personal responsibility to health. It is a challenge and responsibility facing the medical specialists. It is essential that the activities connected to health promotion be more widely spread and distributed through giving correct and competent medical information for the behavioral risk factors and the ways of overcoming them. The effective control over the individual risk profile and the timely correcting actions in a devitalized way of life guarantee active and sufficient old age.

IRTIIE Vol. 5, No. 3, 2017 ISSN 1314-8788 (print), ISSN 1314-8796 (online), doi: 10.15547/artte.2017.03.011 


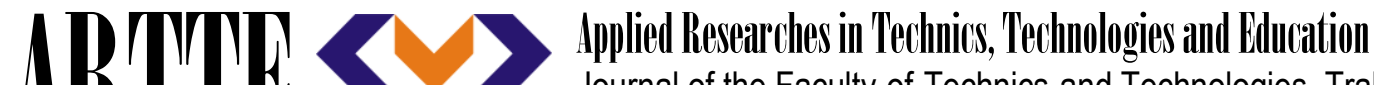 Journal of the Faculty of Technics and Technologies, Trakia University https://sites.google.com/a/trakia-uni.bg/artte/}

\section{REFERENCES}

[1] Milcheva B., Socio-medical problems of obesity - autothesis, Sofia 2016.

[2] National health strategy - 2014-2020.

[3] National program for prevention against non-contagious chronic diseases 2014-2020.

[4] Stoynev G. Social gerontology. MIF, Sofia 1986.

[5] Tsvetkov D., Hygiene and ecology, volume I, Znanie EOOD, 1999.

[6] Vodenicharov Ts., S. Popova, M. Mutafova, E. Shipkovenska - Social medicine, Sofia 2013.

[7] http://www.medlinks.ru/article.php?sid=45738.

[8] http://www.segabg.com/article.php?id=797361.

[9] http://www.who.int/dietphysicalactivity/fruit/en/.

[10] http://www.who.int/mediacentre/factsheets/fs393/en/. 